TRANS $\cdot$ núm. $24 \cdot 2020$

DOSIER $\cdot 17-32$

En la era globalizada y de comunicación de masas, los medios y la publicidad crean corrientes de opinión y diseñan estilos de vida a gran escala. Mediante el estudio de campañas publicitarias de la casa Rolex se comprobará en qué medida estos discursos pueden contribuir a fijar una identidad femenina alejada de la representación estereotípica y nociva que se ha venido dando en los últimos años, haciendo que la traducción sirva como herramienta de entrada de ideologías alternativas.

PALABRAS CLAVE: postraducción, traducción publicitaria, reescrituras, traducción periodística, identidad.

\title{
Postraducciones publicitarias de la mujer: las reescrituras alternativas de Rolex
}

IRENe RodríGuez Arcos

Universidad de Salamanca

\section{Advertising Post-translations of Women: Rolex alternative rewritings}

In times of globalisation and mass communication, media and advertising create opinion trends and design lifestyles at a global level. The study of Rolex advertising campaigns will show to which extent these discourses can contribute to fix a feminine identity, different from the stereotypical and harmful representation which has been a tendency in the last few years, so translation works as the way of entrance of alternative ideologies.

KEY WORDS: post-translation, advertising translation, rewritings, journalistic translation, identity. 
1. INTRODUCCIÓN: NUEVAS FORMAS DE TRADUCCIÓN EN LA SOCIEDAD GLOBAL DE CONSUMO

En la sociedad actual los estímulos del consumo se dirigen a sus potenciales receptores a través de nuevos signos y lenguajes. Estas nuevas formas de comunicación ahora vienen codificadas en forma de imágenes, sonidos, colores, voces o movimientos que, junto a los elementos lingüísticos tradicionales, conforman una compleja maquinaria semiótica que se cuela entre las grietas de nuestra mente y nos seduce sutilmente para lograr que el sistema mercantil siga su curso.

Ciertos discursos publicitarios (Valdés, 2004) y mediáticos, en la era global, logran traspasar fronteras lingüístico-culturales de la mano de las nuevas tecnologías y medios de comunicación de masas, que operan desde un centro claro hacia otras zonas periféricas, donde se localizan (Bielsa, 2016) y se adaptan en gran medida mediante prácticas que desafían las definiciones más tradicionales de la disciplina (Valdeón, 2018; Hernández, 2018). En este sentido, no pueden ignorarse los retos que estas representaciones mediáticas suponen para la traductología, que obligan a los académicos a repensar sus límites y a expandir su campo y objeto de estudio, que ya no se limita meramente al plano lingüístico y verbal (Gentzler, 2017). El objetivo del presente artículo será analizar una muestra de estas nuevas formas de traducción en términos lingüísticos y semióticos, que solo cabe entender en un sentido amplio en este subcampo de la disciplina, para hacer frente a los desafíos de la era global:

This kind of writing invites us to go beyond that term [translation], which has come to acquire such a restricted meaning, so as to reconceptualise translation as movement between and across, not simply as a transaction between a source and a target text. [...] The idea of transposition is etymologically present in the word «translation», which implies movement across time and space and, [...] translation underwrites all our cultural transactions in this multifaceted, globalised world of ours (Bassnett, 2011: 244).

Concretamente, nos ocuparán las reescrituras del cuerpo femenino en dos campañas de la multinacional Rolex, una impresa en una revista de alta gama y otra de la web de la casa, ambas en sus versiones inglés-español, que permitirán comprobar cómo la globalización homogeniza modelos de identidad y hábitos de consumo (Bauman, 2000), además de arrojar luz sobre la construcción social de la mujer en un momento histórico en el que el feminismo ha logrado entrar en debates y espacios públicos (Beard, 2017; Santaemilia, 2014 [2005]). Quizá este hecho nos haya hecho conscientes de que ahora, más que nunca, nos hallamos inmersos en lo que Turner (2009) denominó «sociedad somática», que consume cuerpos representados:

The consumption of images is a crucial aspect in this context, with images of the body in particular predominating. In fact in a consumer culture, the material fabric of everyday life — social spaceseems to be specifically designed in order to facilitate the display of the body (open-plan spaces, mirrors and glass in restaurants, shops and shopping centres, for example) (Fraser y Greco, 2007 [2005]: 27).

La sociología del cuerpo se ha convertido en un ámbito candente en la academia que no solo está presente en la sociología y en el feminismo, sino que también ha pasado a ser parte de la traductología. En la línea de autoras como Federici y Parlati (2018) o Vidal Claramonte (2018a), nuestra hipótesis de partida se basa en que el cuerpo representado se convierte en un texto; es decir, 
en una superficie de inscripción ideológica (Foucault, 2002 [1975]; Turner, 2009) y de poder(es), de lectura y, por lo tanto, de (post-)traducción (Gentzler, 2017), concepto en el que se profundizará en el siguiente epígrafe. En este sentido, pasa a ser un elemento semiótico transmisor de significado que comunica y forma parte de los engranajes que conforman el discurso visual (Barthes, 1977). A través de los casos de estudio seleccionados se observará qué mensajes utiliza la casa para venderse, si coinciden los valores en las campañas postraducidas en cada lengua y en qué medida la traducción ayuda a construir modelos identitarios que difieren de otras representaciones clásicas de la figura femenina en publicidad (Rodríguez Arcos, 2019). Para llevar a cabo este análisis multidisciplinar, en primer lugar se ofrecerá la definición de traducción a la que se acoge este artículo, que necesariamente ha de ir más allá del plano verbal, y se especificará la metodología empleada.

\section{EXPLORANDO NUEVOS LÍMITES: LA POSTRADUCCIÓN EN EL ÁMBITO MEDIÁTICO}

En palabras de Gentzler, nos hallamos en un momento histórico en el que «translation studies need to reinvent itself, coming up with more inclusive parameters, more fluid theories, and more incisive socio-psychological analysis, to better understand translation and rewriting in the post-translation age» (2017: 231). Esta propuesta de ampliación de la definición tradicional de la disciplina, que se había entendido tradicionalmente en el sentido «interlingüístico» que le otorgaba Jakobson (1959), permite, entre otras cosas, desestabilizar los originales y difuminar la clásica distinción entre texto origen y texto meta, una dicotomía que pierde todo su valor en este subcampo al elaborar campañas casi homo- géneas para varios mercados y culturas (Montes Fernández, 2007; Cronin, 2003). Los textos periodísticos y publicitarios se convierten así en unos candidatos excelentes para aplicar dicha ampliación de la definición, ya que las noticias que se consumen suponen, desde esta perspectiva, postraducciones de la realidad:

Post-translation studies looks at the complex mo-
vement of texts, not just source to target, but to
target and beyond, west to east, north to south,
linear to non-linear, texts to images, and forward
in time and space through multiple languages,
cultures, and genres (Gentzler, 2017: 112-113).

Otro de los términos que ha suscitado el debate de la ampliación de los límites de la disciplina es el de la «transcreación», ampliamente aplicado a textos periodísticos y publicitarios, como es el caso de la muestra estudiada en este trabajo. Si bien es cierto que ciertas voces abogan por distanciarse de lo que se ha considerado traducción y lo consideran como una actividad que va más allá (en el sentido de que se pueden crear nuevos originales, se habla de técnicas orientadas al contexto meta, etc.), autores como Pedersen recuerdan que la traductología había ofrecido esos enfoques teóricos con obras ya consideradas canónicas, desde Jakobson hasta la cuestión de la equivalencia dinámica propuesta por Nida, así como los aportes de Nord o Reiss y Vermeer (Pedersen, 2014: 68-69). En este sentido, aunque puedan darse aspectos de solapamiento entre ambas nociones, son ya numerosos los trabajos que han respaldado esta ampliación de la disciplina en ciertos subcampos.

La traducción periodística lleva estudiándose unos veinte años (Valdeón, 2020) y, desde entonces, siendo objeto de polémica dadas las prácticas que tienen lugar en este subcampo, como la combinación de más de un original en lo que supone un solo texto fuente, las adiciones 
20 u omisiones de segmentos y párrafos completos por razones de espacio y sesgo ideológico, o la reestructuración de información; un nivel de intervención que cuestiona que el texto final vendido a los medios constituya una traducción en sentido estricto al existir tal grado de manipulación y edición previa (Bielsa y Bassnett, 2009). En este sentido, se desestabilizan pilares tradicionalmente sagrados en otros ámbitos de la disciplina, como por ejemplo la equivalencia (Toury, 1980). Bielsa y Bassnett (2009), a lo largo de su estudio, recogen trabajos de campo en el seno de grandes agencias de comunicación globales de la talla de Reuters, Agence France Presse o Associated Press. Estos gigantes de la comunicación funcionan como agentes globalizadores en la medida en la que diseñan y exportan flujos de información que sirven, sobre todo, a la hegemonía occidental y a su élite política y económica. Estas agencias, además de los periódicos nacionales que compran sus textos, realizan el llamado gatekeeping o filtrado descrito por Valdeón (2018) antes de publicar las noticias. En primer lugar, el gatekeeping se da a nivel institucional, y se selecciona lo que es publicable (y lo que no, queda fuera del consumo, no está disponible para el receptor como opción); y, en segundo lugar, existe además un gatekeeping individual del que es responsable el redactor-traductor-periodista, que realiza estas tareas al editar sus textos (Bielsa y Bassnett, 2009; Valdeón, 2018), siguiendo la línea editorial e ideológica del medio que lo acoja.

Si en la prensa considerada seria es obvia la presencia de estos sesgos y manipulación, en el caso de las revistas femeninas de alta gama resulta especialmente revelador (Gallego, 2013; Páez Rodríguez, 2016). Normalmente, en estas publicaciones, las narrativas (Baker, 2006) presentadas se adaptan a las que pretenden vender los anunciantes que financian a las revistas, tí- picamente en la línea de mantener un cuerpo bello, joven y esbelto (Rodríguez Arcos, 2019; Gallego, 2013). Sin embargo, en los casos de estudio que se analizarán a continuación, la casa se distancia de estas representaciones monolíticas y estereotípicas (Bhabha, 2004; Nardi, 2011) que son nocivas para la construcción social del género femenino, concentrándose en los méritos laborales y sociales de las mujeres que muestra y apostando por la inclusión de mujeres de edad avanzada (Gallego, 2013; Hofstede, 1998). En este sentido, la publicidad incluida en ciertos medios de comunicación no es casual: los contenidos de cada publicación están pensados para proyectar ciertas narrativas en conjunto (Hernández Guerrero, 2012); una ideología que, en el caso de las revistas femeninas, suele ir en la línea del control de la identidad y del cuerpo de la mujer:

Desde su nacimiento, las revistas femeninas (paradójicamente, o quizá lógicamente, dirigidas y pensadas por mujeres) han ido construyendo un ideal de mujer mediante la inscripción en él de los significados sociales impuestos; y todo ello se ha conseguido al entender el cuerpo femenino como un texto que se iba configurando a través de los textos que lo acompañaban, textos que van dirigidos a la creación de una identidad controlada y estable que se adapte a un sistema regulado desde el patriarcado y que no hace más que perpetuar determinados tipos de representación que dan lugar a construcciones ficticias de la identidad (Vidal Claramonte, 2012: 1032; énfasis añadido).

\section{LA NARRATIVA DEL ÉXITO DE ROLEX EN REVISTAS DEPORTIVAS Y FINANCIERAS}

Contrariamente a lo que se ha asentado como norma en diferentes tipos de publicidad presente en revistas femeninas de alta gama (representaciones sexualizadas de mujeres jóvenes y muy delgadas) (Rodríguez Arcos, 2019; Vidal, 
2012), la casa Rolex ha optado por distanciarse de este tipo de prácticas en la muestra analizada $y$, aunque se anuncia en dicho tipo de medios (como se comprobará en uno de los casos de estudio presentados a continuación), prefiere marcar un aire de distinción asociada a otro tipo de publicaciones, como las revistas deportivas o de negocios. Así lo hizo en diciembre de 2018, año de manifestaciones y marchas históricas en el Día de la Mujer, en la revista de golf $H K$ Golfer, en la que apareció un artículo titulado «Rolex and inspiring women». La presencia de «inspiring» no es en absoluto casual, pues ese es el nombre de la colección Rolex objeto de estudio de este artículo (traducido al español como «fuente de inspiración»). El texto recuerda en cierto modo al de las revistas femeninas de alta gama por su alto contenido publicitario camuflado entre lo que es propio de la revista (Gallego, 2013). Con segmentos como «every woman who wears a Rolex has an inspiring history», combaten la narrativa de la presencia tradicional de la mujer en arte y publicidad como ente pasivo, sin voz ni actividad:

[M]en act and women appear. Men look at women. Women watch themselves being looked at. This determines not only most relations between men and women but also the relation of women to themselves. The surveyor of woman in herself is male: the surveyed female. Thus she turns herself into an object - and most particularly an object of vision: a sight (Berger, 1972: 45).

Asimismo, afirman «the Rolex they proudly wear is an emblem of those who meet challenges» y destacan que «women have been at the heart of Rolex's success since the company first opened its doors». En realidad, desde los inicios apostaron por representar a mujeres cuyos logros profesionales y deportivos fueran destacables, como el caso de Mercedes Gleitze, que se convirtió en la primera mujer británica en atravesar a nado el Canal de la Mancha en 1927 luciendo el modelo Oyster de la casa, como afirman los gestores de contenidos en su propia web ${ }^{1}$. Se puede observar que la estrategia no es en absoluto novedosa; y parece ser que ha dado resultado desde hace cerca de un siglo (la fecha de dicha campaña es 1927); aunque no se puede descartar que hayan decidido rescatar ciertas narrativas dada la presencia actual del feminismo en el panorama político, económico y social: «These Rolex Testimonees are changing the world, and the way the world sees women»; «Their courage and perseverance are an example to all, inspiring both men and women of all generations to greatness» (HK Golfer, 2017). En el artículo se concentran en los méritos de las golfistas Lydia Ko y Annika Sörenstam, cuyos testimonios aparecen en la página web de la multinacional y en anuncios vendidos en revistas femeninas con su imagen. Entendemos que la marca pretende distinguirse marcando el elitismo de sus consumidoras difundiendo ciertos valores simbólicos asociados al deporte (esfuerzo, constancia, perseverancia) y haciendo que se «identifiquen» con ellos:

Etiquetas, logos y marcas son los términos del lenguaje de reconocimiento. Lo que uno espera ser - y como norma es ser «reconocido» con la ayuda de etiquetas, logos y marcas - es lo que en años recientes se ha dado en llamar identidad. La operación descrita antes muestra la preocupación por la «identidad» como aspecto central de nuestra sociedad de consumo. Mostrar «carácter» y gozar de una «identidad» reconocida, así como encontrary obtener los medios que aseguren estos propósitos interrelacionados se convierten en las principales preocupaciones en la búsqueda de una vida feliz (Bauman, 2009 [2008]: 23).

I Rolex (2020): «1926-1945. Hitos de la relojería. Historia de Rolex». Disponible en: https://www.rolex.com/es/aboutrolex-watches/1926-1945.html [Último acceso: 24 de junio de 2020]. 
22 Y así lo demuestra uno de los testimonios de Annika Sörenstam recogidos en el artículo de $H K$ Golfer, que reconoce que la marca valida su identidad personal y le da confianza:

Rolex and I built up a friendship and a partnership. Obviously, to be picked up by somebody of that calibre gave me a confidence boost, and I am still to this day very proud to be an ambassador. For me personally, it was like, «Wow, this is validation».

La edición en línea de la conocida revista Forbes también recoge el espíritu de la marca de destacar los logros de las mujeres con el titular «Rolex Celebrates the Pioneering Spirit of Women» (Salonga, 2017). De igual manera que la revista deportiva, mencionan que la marca lleva promocionándose con la misma estrategia desde 1927, con la hazaña de Gleitze, e incluyen una imagen de dicha campaña impresa de Rolex en blanco y negro en la que aparece la nadadora promocionando el modelo Oyster. A lo largo del artículo, se menciona a diferentes personalidades y sus logros profesionales o el palmarés, en el caso de las deportistas: Meredith M. Beerbaum, tres veces campeona mundial de hípica; Sylvia Earle (bióloga marina que constituirá el segundo caso de estudio aquí presentado); Garbiñe Muguruza (cuya campaña se analizará en el siguiente epígrafe); Sonya Yoncheva, del mundo de la ópera; Lindsey Vonn, cuatro veces campeona mundial de esquí, o Yuya Wang, reconocida pianista a nivel mundial. Este contenido web, que Forbes decide clasificar en la sección de estilos de vida, perpetúa la narrativa del medio en el que se encuentra (Hernández Guerrero, 2012), que es la misma que vende la casa: todo esfuerzo tiene su recompensa (en este caso, una considerable suma económica que permite al comprador acceder a un producto de precio elevado); una narrativa que se volverá a observar en el caso de estudio de Garbiñe Muguruza, en palabras de la propia tenista: «Mis padres renunciaron a todo lo que tenían para que pudiera convertirme en una tenista profesional. He aprendido que los sacrificios tienen su recompensa».

\section{METODOLOGÍA Y DESCRIPCIÓN DE LA MUESTRA}

Como se viene apuntando, la marca ha optado por marcar un aire de éxito y distinción en diferentes momentos de su historia. En la web de la casa (disponible en veinte idiomas, puede hablarse de contenidos globales), encontramos lo que los anunciantes han decidido llamar «El mundo de Rolex» ${ }^{2}$, un menú en el que se relatan las exclusivas esferas con las que se relaciona la marca: deportes asociados a cierto aire de élite como el tenis, la hípica, la vela o el automovilismo. Asimismo, bajo la denominación «arte y cultura», se puede hacer clic en «Rolex y el cine», «Rolex y la arquitectura», «Rolex y las artes», hasta encontrar colaboraciones con ciencia y exploración. Como se ha mencionado en el epígrafe anterior, el motivo de selección de estas campañas reside en que proyectan una ideología más respetuosa con la construcción social de la mujer que las que se observan en revistas femeninas (Rodríguez Arcos, 2019; Vidal, 2012) o incluso prensa general o deportiva (Rangel y Ramírez, 2018). Si bien es cierto que la denuncia de ciertas prácticas publicitarias está cada vez más presente en un momento en el que el feminismo está debatiéndose públicamente, en ocasiones se echan en falta estudios que recojan otro tipo de voces y corrientes, dignas de celebrar. Sin embargo, conviene apreciar que se trata de un «mito» barthesiano más, que trata de

\footnotetext{
2 Disponible en la dirección: https://www.rolex.com/es/ world-of-rolex.html [Último acceso: 24 de junio de 2020].
} 
deslizar la idea de que se pone el foco en la figura femenina: tras un análisis más detenido se percibe que en toda la web se relatan las historias de veintiún hombres, frente a once mujeres, lo que constituye apenas la mitad de la cifra.

La primera campaña estudiada se publicó en el número 2018 de febrero de la revista Vogue, que puede clasificarse como una publicación femenina de alta gama (Gallego, 2013). En ella aparece la tenista Garbiñe Muguruza (25 años en el momento de la publicación) promocionando el modelo «Oyster Perpetual Datejust 36». Resulta llamativo que solo se observara en esta publicación una campaña como esta, celebrando los logros de la figura femenina, a pesar de que suelen repetirse (Rodríguez Arcos, 2019), en un año en el que el feminismo tomó las calles de forma histórica, y otras cabeceras de características similares, como Marie Claire $^{3}$, dedicaran parte del número de ese mes a destacar los logros de mujeres. La segunda campaña recoge a Sylvia Earle en la propia web de $\operatorname{Rolex}^{4}$ (83 años en el momento de la publicación), promocionando el modelo «Oyster Perpetual Lady-Datejust». A pesar de estar insertada en la web, resulta relevante por recuperar la estética de la versión impresa publicada en revistas ${ }^{5}$ y por constituir un modelo identitario de sabiduría y experiencia, así como de edad avanzada.

En lo que respecta a la estructura del análisis, en primer lugar, se analizará el plano verbal de las campañas, donde se prestará especial aten-

3 Muestra de la portada y parte de los contenidos de dicho número disponible en: https:/www.marie-claire.es/ lifestyle/revista/articulo/ya-esta-aqui-el-numero-de-febrero-de-marie-claire [último acceso 29 de junio de 2020].

4 Disponible en la dirección: https:/www.rolex.com/es/ world-of-rolex/every-rolex-tells-a-story/sylvia-earle-rolexwatch.html [Último acceso: 24 de junio de 2020].

5 Ejemplo de la versión impresa de la campaña en lengua inglesa disponible en: https://cutt.ly/bidiK91 [Último acceso: 25 de junio de 2020]. ción a aspectos como la ideología y el poder (Tymoczko y Gentzler, 2002), destacando las connotaciones del lenguaje, que teóricos como Vidal Claramonte (2013) y Grijelmo (2014 [2000]) han denominado «ruidos» y «aromas», respectivamente. Ambos conceptos están muy relacionados entre sí: mientras que para Vidal (2013: 16) el traductor tiene que saber que «cada palabra siempre evoca, nunca viene sola, siempre se escucha ligada a ruidos, que son diferentes según quién pronuncie o traduzca esa palabra» $\mathrm{y}$ reconocer esos ruidos, para Grijelmo «la seducción de las palabras, su olor, el aroma que logran despertar aquellas percepciones prehistóricas, reside en los afectos, no en las razones» (2014 [2000]: 39). También nos apoyaremos en los trabajos de Barthes (1999 [1957]), en especial en los conceptos de «mito»y «significados de primer y segundo orden», que serán de utilidad para no asumir automáticamente ciertos discursos mostrados de forma aparentemente lógica (significados de primer orden), pero que tras un análisis profundo resultan ser sistemas de valores arbitrarios, diseñados desde una lógica mercantil para que el público se adhiera a ellos (significados de segundo orden). Entre estos ruidos y connotaciones, lo primero que cabe destacar es que, a nivel verbal, se observa un dominio del inglés en el caso de los vídeos de la web que apoyan las campañas y los testimonios, incluso en el caso de Garbiñe Muguruza, nacida en Venezuela y competidora por España en los grandes torneos (de la que quizá podría esperarse que hablase en español) (Páez, 2016).

Por último, se tratará el plano semiótico, es decir, las postraducciones mediáticas del cuerpo femenino; unas representaciones que pueden relacionarse con el plano verbal gracias a la ya mencionada ampliación de la definición de la disciplina, en la línea del concepto de «traducción intersemiótica» que Jakobson 
24 (1959) proponía hace décadas. Para abordar este terreno, nos resultan especialmente relevantes los women \& media studies (Gallego, 2013), que ayudan a entender la relación de las mujeres con su propio cuerpo, así como las aportaciones de Berger (1972) o Subiela (2010), que permiten profundizar en lo que esconden la imágenes.

\section{ANÁLISIS DE DOS REESCRITURAS MEDIÁTICAS FEMENINAS}

\subsection{Rolex y el tenis: Garbiñe Muguruza en revistas femeninas de alta gama}

Para este primer caso de estudio, se han seleccionado las versiones en inglés y en español de la campaña de Garbiñe Muguruza que aparece impresa en el número de febrero de 2018 de Vogue, una publicación que puede encasillarse en las revistas de alta gama (Páez, 2016). Existen otros anuncios muy similares en ambas lenguas con algunas de las figuras femeninas mencionadas anteriormente: deportistas de élite que aparecen retratadas con clase y elegancia huyendo, como se ha apuntado, de representaciones estereotípicas en las que la mujer aparece sexualizada o como objeto de deseo (Rodríguez Arcos, 2019). Los creadores optan por fotografiarlas a la altura del torso o, en alguna ocasión, de cuerpo entero, y, si es así, vestidas con colores grises o negros y poses neutras.

En línea con el público receptor de la revista (Gallego, 2013), la campaña parece estar dirigida a mujeres con elegancia, clase y éxito con el eslogan «inspiring», traducido al español como «fuente de inspiración». El eslogan en sí mismo ya es muy revelador. Representa a las mujeres escogidas como un modelo a seguir, y lo que suscita la admiración (Berger, 1972: 132) es una trayectoria profesional fuera de lo común, cuyo éxito les permite optar a un reloj de esas características. A nivel lingüístico, «fuente» es un término cargado de ruidos positivos (Grijelmo, 2014 [2000]; Vidal Claramonte, 2013), al igual que «inspiración». A la derecha de la foto y en letra pequeña se ofrece un breve currículo de la mencionada deportista como imagen de la campaña: «Desde que pisó las pistas con tres años, no ha cejado en su empeño de ser la mejor». El discurso ganador, que dota de autoridad y capital simbólico al producto (Fowler et al., 2015), se aplica tanto a ella como a la marca y al producto, así como a las oraciones que siguen: «Motivada por su gran pasión por el tenis, da lo mejor de sí cada vez que sale a jugar»: en esta ocasión, la «pasión» es tanto de Muguruza como de los relojeros de la casa, que hacen la maquinaria perfecta. «Su estilo de juego, potente y apasionado, le ha valido dos títulos de Gran Slam»: de nuevo, narrativas de éxito y esfuerzo (Baker, 2006), que ahora se entretejen con lo que resaltan sobre un fondo azul en tipografía blanca y de mayor tamaño, «un esfuerzo que dará su fruto».

«Rolex está orgulloso de colaborar con Garbiñe Muguruza, cuyo ascenso a la cumbre mundial del tenis solo acaba de empezar»: aparentemente, la marca le da las gracias a ella, configurando así un mito barthesiano de reconocimiento, cuando se ha apuntado anteriormente que en realidad la marca recoge como testimonio de sus embajadoras el agradecimiento por el patrocinio que ofrece una multinacional como Rolex. También es notable el tratamiento con nombre y apellidos, y no de forma demasiado familiar, como sucede en numerosas ocasiones en el mundo de la información cuando llaman a las mujeres únicamente por su nombre de pila (Gallego, 2013). Además se establece una metáfora con el mundo del montañismo que da cuenta nuevamente de los valores del empeño que tratan de vender (ella 
es deportista de élite). Por último, dos oraciones finales que también se repiten en las versiones en inglés (traducidas literalmente): «No solo marca el tiempo. Marca su época» («It doesn't just tell time, it tells history»). Se refieren tanto a la deportista como al reloj (como también lo hace la postraducción).

Sobre un fondo azul marino y en letra blanca mayúscula se ofrece una cita de Garbiñe Muguruza, acompañada de su firma y dos frases que sitúan rápidamente a la receptora en contexto en caso de que no conozca a la mujer de la imagen, destacando sus éxitos profesionales. «Hay que ser tenaz y perseguir sin descanso lo que se desea. Al final, todo ese esfuerzo dará fruto». Destacan la tipografía de «tenaz», «lo que se desea», «todo ese esfuerzo» y «dará fruto» con la clara intención de atraer la atención del lector sobre la carga ideológica del mensaje. Los aromas y ruidos (Grijelmo, 2014 [2000]; Vidal Claramonte, 2013) de «tenaz» se relacionan con los de «esfuerzo», pero también con los del currículo del fondo blanco de los términos «potente» y «apasionado», así como la construcción "perseguir sin descanso», que proyectan la misma narrativa. Terminan con «todo ese esfuerzo dará fruto», que también podría interpretarse en la línea de que, después de labrarse un gran futuro profesional, pueden permitirse un producto como un reloj de esta marca, que es «lo que desean» (Bauman 2003 [1998]). Finalmente se observa la firma, un autógrafo de la tenista, por lo que se entiende que se vende casi un producto de autor, que hace que el consumidor le otorgue un gran capital simbólico. Además de al producto anunciado, la receptora se adhiere a los valores de esfuerzo y éxito de la deportista, que además está presentada con un aire de ele- gancia innegable ${ }^{6}$ : ligeramente maquillada, melena cuidada, camisa blanca de lo que parece ser seda o raso, el reloj y una mano delicadamente apoyada sobre la otra.

En la versión inglesa, el anuncio es prácticamente equivalente a nivel lingüístico y semiótico. Se relatan de igual manera los logros profesionales, en los cuales no se profundizará por limitación de espacio y por tratarse de un texto que coincide a nivel interlingüístico (Jakobson, 1959). Como se ha adelantado de forma breve, el eslogan en inglés es el siguiente: «It doesn't just tell time, it tells history» (en español, «no solo marca el tiempo, marca su época»). Aunque evoca valores parecidos, el verbo principal no es «marcar», como en español, que hace referencia claramente a las agujas del reloj; sino «tell», ya que en inglés la colocación es «tell the time». Sin embargo, merece la pena profundizar en la segunda parte del eslogan sobre todo, que configura otro mito barthesiano al deslizar el significado de que «cuenta la historia», la construye lingüísticamente incluso (Potter, 1996; Vidal Claramonte, 2018b), trayendo los logros profesionales de la deportista (y de otras figuras a las que patrocina la marca), que queda inmortalizada documentalmente (Barthes, 1977) luciendo el reloj.

La cita destacada sobre el fondo azul esta vez es la siguiente: «You have to be strong and keep fighting for what you want. In the end, the hard work will pay off». Se trata de una traducción interlingüística (Jakobson, 1959) prácticamente equivalente, de la que se destacan los mismos segmentos que en la versión española. Aparece «strong» por «tenaz», la idea del esfuerzo sos-

\footnotetext{
6 Aunque se redirige a la versión inglesa de la campaña por cuestiones de accesibilidad, la imagen es idéntica en ambas versiones del anuncio. Disponible en: http://www.jwcodling.com/rolex-womens-campaign/2017/2/15/womenscampaign-2017garbine-muguruza15 [Último acceso: 25 de junio de 2020].
} 
26

tenido se construye a través de «keep» seguido del gerundio «fighting», que evoca ruidos (Vidal Claramonte, 2013) parecidos a los de «perseguir sin descanso» y, por último, «pay off» para «dar su fruto», que recoge narrativas de éxito y recompensa (económica, como ya se ha apuntado).

A continuación se tratará el plano semiótico de ambas campañas, exactamente igual en ambas versiones. El producto se muestra en la esquina inferior derecha y lo luce la deportista (en algunas campañas impresas con otras embajadoras ni siquiera se muestra el reloj en las fotografías, como en la versión del anuncio de Lindsey Vonn ${ }^{7}$ ). Aparece vestida con una blusa blanca, sencilla y elegante, y no se alcanza a ver más que el rostro o las manos, sin ningún intento de sexualización o de mostrar el cuerpo de la deportista. Por otro lado, los colores oscuros del diseño de la campaña, con bajos grados de saturación, son postraducciones de narrativas como la sobriedad, la inteligencia o la elegancia (Subiela, 2010: 171-175). Mediante toda esta maquinaria semiótica cuidadosamente seleccionada (Vidal Claramonte, 2012), los creadores pretenden transmitir a sus potenciales consumidoras unos valores de clase y elegancia, a la vez que independencia económica.

\subsection{Rolex y la ciencia: Sylvia Earle como representación de modelos de edad avanzada}

En este caso, se toma la publicidad insertada en la web de la casa, en la que recurren a la bióloga marina Sylvia Earle. Resulta interesante en la medida en la que optan por incluir mujeres de edad más avanzada, silenciadas en otros ámbitos (Gallego, 2013) y por encarnar otro tipo de valores diferentes a los de estas deportistas

Disponible en la dirección: http://www.jwcodling.com/ blog [Último acceso: 24 de junio de 2020]. jóvenes y en forma. Al haber comprobado que esta versión también aparece impresa en revistas femeninas de alta gama, se puede descartar que solo opten por esta estrategia de representación en su web, donde la casa no se ve obligada a perpetuar las narrativas de otros anunciantes o de la revista en sí (Hernández Guerrero, 2012). En este caso, los publicistas han optado por vender la narrativa del éxito a través de los logros cosechados por medio de la ciencia, el conocimiento y la investigación.

En la web, bajo el lema «cada Rolex tiene una historia que contar», aparece el nombre de la embajadora y una pequeña introducción de su biografía y del producto. En esta ocasión, enlazan a un vídeo de YouTube de la marca en el que aparecen fotografías de Sylvia Earle a lo largo de su vida, así como ella misma hablando (se mantiene el inglés en la versión en castellano y se puede activar la subtitulación si el espectador lo desea, al igual que Garbiñe Muguruza en la versión audiovisual que ha diseñado $\operatorname{Rolex}^{8}$ ) acerca de su trayectoria vital y del significado que le confiere al producto. El texto del vídeo puede considerarse un resumen del contenido web, que incluye en primer lugar imágenes de la bióloga y, luego, según se desliza el menú hacia abajo, aparece un primer plano del producto en su muñeca y, finalmente, el producto de forma independiente.

A nivel verbal, tanto la versión inglesa como la española en línea coinciden prácticamente en sentido interlingüístico (Jakobson, 1959). Al igual que en el caso anterior, por cuestiones de espacio, se destacarán solamente algunos segmentos especialmente significativos de cara a configurar la identidad femenina y los valores de

8 Disponible en la dirección: https://www.rolex.com/es/ world-of-rolex/every-rolex-tells-a-story/garbine-muguruza-rolex-watch.html [Último acceso: 24 de junio de 2020]. 
la casa. Así, desde el principio del texto los publicistas advierten de que no se trata únicamente de un accesorio:

[ES] El tiempo, como ella misma explica, es una medida de la vida y un recordatorio de que cada individuo puede marcar la diferencia. El reloj Rolex que lleva no es solo un reloj de confianza en sus expediciones, sino que tiene un significado mucho más profundo.

[EN] Time, she explains, is a measure of life and a reminder that each individual can make a difference. The Rolex watch she wears is not only a trusted timepiece on expeditions, but carries deeper meaning.

De esta manera, mediante el segmento «es una medida de la vida» («measure of life») y «marcar la diferencia» («make a difference»), se establecen conexiones entre las narrativas de la biografía de Earle y el producto en sí, que la acompaña siempre. En español, la colocación propia del idioma «marcar la diferencia» sirve para reforzar esta ideología. A continuación, en tipografía blanca destacada (de la misma forma que la campaña impresa), incluyen una cita de la propia Earle: «Lo que me encanta de sumergirme en el océano es que nunca sabes lo que te vas a encontrar, pero sí sabes que va a ser bueno» («What I love going under the surface of the ocean is you never know what you're going to find, but you know it's going to be good»). De nuevo, el mismo mecanismo para configurar la narrativa de que se trata de una suerte de producto de autor, confiriéndole aún más exclusividad, si cabe. De hecho, al final del menú web, encima del nombre del modelo en cuestión, dicen que es «El reloj de Sylvia Earle». En esta línea de dotar de un significado de segundo orden al producto y convertirlo en mito (Barthes, 1999 [1957]), afirma lo siguiente la bióloga:
[ES] Normalmente, consideramos los relojes como artículos de joyería o como equipos para indicar el tiempo, en el caso de los exploradores. Sin embargo, mi reloj tiene un significado mucho más profundo para mí. [...] Y para mí, llevar este reloj es como una firma: equivale a decir que esas cosas te importan, que compartes esa ética de cuidar lo que te rodea.

[EN] Most watches are looked upon as jewellery or - for us explorers - as an equipment to tell the time, but my watch to me has a much deeper meaning. [...] So for me, wearing it, it's like a signature, you care about those things too, you share something with the ethic of caring.

A lo que se refiere el texto es a lo que en el cuarto epígrafe se introdujo como el «Mundo de Rolex», es decir, las colaboraciones que establece la marca con disciplinas muy variadas en las que han decidido destacar figuras de éxito. De nuevo, y en tipografía destacada, dirigen la atención del lector hacia la siguiente cita de Earle:

[ES] El concepto de Rolex se basa en apoyar la exploración, la conservación, las artes y todo aquello en lo que los seres humanos podamos dar lo mejor de nosotros mismos.

[EN] The concept of Rolex is supporting exploration, conservation, the arts and the best that humans can be.

De esta manera vuelven a aparecer los valores del esfuerzo que encarnaba Garbiñe Muguruza («dar lo mejor de nosotros mismos»; «the best that humans can be»), junto con el patrocinio de ciertas esferas exclusivas, con las que pretenden establecer mecanismos de identificación con el receptor (Bauman, 2009 [2008]) para salirse de lo común. Sin embargo, también ofrecen una narrativa antagónica mediante la cual el público también ha de considerar el producto como algo que puede lucir en cualquier ocasión. Esta vez, 
28 la bióloga, recordando la primera vez que vio un Rolex, habla de cómo su mejor amiga lo sumergió en el agua:

[ES] Pensé que se había olvidado de quitarse el reloj, pero ella simplemente sonrió. Entonces comprendí que se trataba de un Rolex y que se podía bucear con él incluso a mucha más profundidad del nivel en el que estábamos en aquel momento. Pero también te lo podías llevar a galas de etiqueta, usarlo bajo la lluvia, ducharte con él...

[EN] I thought she had forgotten to take off her watch, but she just gave me this smile. Only then I saw that it was a Rolex and it was quite capable of diving, not just as deep as we were at the time, but it could go much deeper. And yet it could go to black tie parties, it could go out on the rain, it could go in the shower ...

No obstante, justo a continuación, la marca hace hincapié en ciertas situaciones exclusivas y atípicas que es muy difícil presenciar de forma cotidiana. Así, Earle afirma haberlo llevado consigo a la Antártida, a varios océanos, a las Naciones Unidas o en reuniones con varios presidentes de los Estados Unidos y altos cargos de varias partes del mundo. Tanto es así, que el reloj es, literalmente, «una extensión de sí misma» (destacado en tipografía de mayor tamaño):

[ES] Este reloj me ha acompañado durante muchísimos años... se convirtió en una extensión de mí misma, algo que iba a utilizar para siempre y en todas partes. Es como tener un sexto sentido en tu muñeca, como si fuera tu guía.

[EN] The watch has been my companion now for many decades... just an extension of me, something I would wear all the time, everywhere. It's like having that sixth sense right there on your arm, as your guide.
En ambas versiones se personifica al objeto con el término "guía», un término cargado de aromas positivos (Grijelmo, 2014 [2000]). En la versión inglesa, además, optan por «companion», un refuerzo más de esa narrativa que se pierde en la construcción española. En el plano semiótico, optan por estrategias parecidas a las de la campaña impresa de Garbiñe Muguruza. Totalmente coincidente en ambas versiones, la bióloga aparece retratada con aires de elegancia y sobriedad, vestida con un traje de chaqueta azul marino y negro, dejando a la vista el Rolex dorado. El maquillaje se aprecia, pero no es recargado. Por otro lado, se destaca la inclusión de una fotografía en la que aparece Earle en un proceso de inmersión dentro de lo que podría ser una cápsula, mirando hacia arriba con una expresión de curiosidad y satisfacción. También se entiende que existe un intento de evocar la curiosidad, el conocimiento y la investigación, de forma que la consumidora tenga referentes femeninos en la ciencia:

Since cultural genealogy has always been masculine, with the incursion of some women alibi, legitimized by the power, the third wave of feminisms, like those of the second wave, advocate contesting our chronic cultural lack of mothers by retrieving and revaluing feminine and feminist protagonists, and recognising their leadership and influence (Godayol, 2018: 105).

\section{DISCUSIÓN DE RESULTADOS}

Con los casos estudiados, se puede argüir que Rolex se vende como una marca global para estas campañas en concreto, tanto en las versiones impresas de la campaña como en la web, en las que mantienen un diseño homogéneo y valores parecidos (Montes Fernández, 2007). Ya se había apuntado en epígrafes anteriores, la página 
está disponible en unas veinte lenguas, accesibles con tan solo hacer clic en el menú. Aunque con una muestra mayor se podrían obtener resultados más generales y comprobar si esta estrategia global se mantiene en otros casos, parece que existen indicios de que pueda ser así. Los valores, asimismo, son plenamente coincidentes en ambas lenguas; algo que se ha observado en el plano verbal en las dos versiones, en las que se ha optado por mantener la equivalencia en el sentido más tradicional del término. En el caso de la tenista, los publicistas se concentran en el esfuerzo del deporte, los logros conseguidos a través de entrenamientos largos y difíciles y, por último, la recompensa (que, se entiende, es de naturaleza económica, entre otras). En la campaña de Earle, por otro lado, se hace hincapié en la investigación y el conocimiento científico, una innovación de la que es responsable una figura femenina, de las que apenas hay referentes en la ciencia (Plaza, 2018).

A nivel semiótico, en ambas campañas los cuerpos femeninos constituyen postraducciones de los valores que vende la casa y de los textos que los acompañan. Ambas embajadoras lucen los relojes en las fotografías, pero la atención del lector se dirige a ellas, aunque el producto también está presente en cierta medida (que sí aparece de forma independiente en el caso de la tenista en la esquina inferior derecha de la campaña, en el marco blanco; y en la web, en una imagen en primer plano de la muñeca de Earle y, finalmente, solo el reloj en la parte de abajo del menú). En los dos casos, aparecen sutilmente maquilladas y vistiendo ropa elegante, que marca el estilo de vida que, se supone, acompaña a un accesorio de estas características. Las expresiones que muestran, no podía ser de otra manera, indican satisfacción (quizá por los logros conseguidos). En la historia de Earle de la web además se observa, ya se apuntó, una imagen en la que aparece ella en una cápsula en el proceso de inmersión, con la mirada hacia arriba (una posible postraducción del amor por la investigación, o de la curiosidad que le suscita). A los publicistas esta vez no les preocupa que no luzca de forma impecable, sino mostrarla haciendo su trabajo bajo el océano.

De forma general, podría afirmarse que esta representación de los cuerpos para el consumo (Fraser y Greco, 2007 [2005]) se orquesta de forma muy sutil, haciendo hincapié en la mujer como un ente activo que no solo posa (Berger, 1972), sino que posee una voz reconocida (Beard, 2017) que tiene algo que aportar (no solo a la publicidad del producto, sino a la sociedad en general). Este efecto se logra al destacar citas textuales de ambas embajadoras, que no solo sirve para crear una suerte de productos de autor y configurar ese «lenguaje de reconocimiento» del que hablaba Bauman (2009 [2008]), sino también para validar su discurso. Sin embargo, estas estrategias, que pueden celebrarse si se comparan con las de otras casas de moda y cosmética, han de tomarse con cautela, pues ya se apuntó en el marco metodológico que destaca la presencia masculina en la web.

\section{CONCLUSIONES}

En la era globalizada y de comunicación de masas resulta evidente que las disciplinas necesitan actualizarse para hacer frente a los nuevos retos transculturales (Bassnett, 2011). En la sociedad del consumo, en la que la publicidad configura ideologías y mensajes mediante nuevos códigos y lenguajes a escala global, la traductología debe actualizarse para poder ofrecer trabajos que profundicen en cómo se articulan los ejes globallocal (Bielsa, 2016) de estos nuevos objetos de 
30 estudio que van más allá del tradicional plano verbal. Esto es posible gracias a nuevas teorías, como la de la postraducción (Gentzler, 2017), que puede constituir un enfoque útil para abordar estos nuevos terrenos mediáticos, objeto de estudio en la academia para la elaboración de manuales de traductología actualizados (Valdeón y Vidal, 2018; Harding y Carbonell, 2018).

Asimismo, se considera que estos nuevos planteamientos solo son posibles desde una óptica interdisciplinar, que combine aportes de otras áreas como la semiótica o la fotografía, como ya hiciera Bachmann-Medick (2009) al inaugurar su «giro traslativo». Entre estos campos epistemológicos, el de la sociología del cuerpo resulta especialmente relevante, ya que en la época actual es innegable que el cuerpo se ha convertido en una herramienta de construcción identitaria y de comunicación ideológica, hasta convertirnos en una «sociedad somática» (Turner, 2009), como se apuntó en el apartado introductorio. Analizar las reescrituras y postraducciones mediáticas de la figura femenina diseñadas para el consumo es más relevante que nunca desde el punto de vista ético de los estudios de traducción (Baker, 2006), ahora que el discurso feminista está cada vez más presente en las esferas públicas. Una sociedad que, como advertía Gil (2000), configura a más de la mitad de su población como muñecas sin voluntad, termina por abonar un terreno fértil para las desigualdades y está condenada a sufrir violencia explícita y simbólica. Por esa razón, con espíritu crítico y sabiendo que aún queda un largo camino por recorrer, se celebran estrategias mediáticas como la de Rolex, que viene funcionando desde hace cerca de un siglo y sigue teniendo validez en la actualidad.

\section{REFERENCIAS}

Bachmann-Medick, Doris (2009): «Introduction: The Translational Turn», Translation Studies, 2/1, 2-16.

BAKER, Mona (2006): Translation and Conflict: A Narrative Account, London/New York: Routledge.

Barthes, Roland (1977): Image, Music, Text, trad. Stephen Heath, London: Fontana Press.

BARTHES, Roland (1999) [1957]: Mitologías, trad. Hector Schmucler, Madrid: Siglo Veintiuno.

BAssnetT, Susan (2011): «From Cultural Turn to Transnational Turn: A Transnational Journey», en Cecilia Alvstad, Stefan Helgesson y David Watson (eds.), Literature, Geography, Translation. Studies in World Writing, Cambridge: Cambridge Scholars Publishing, 67-80.

Bauman, Zygmunt (2009) [2008]: El arte de la vida. De la vida como obra de arte, trad. Dolors Udina, Barcelona: Paidós.

Bauman, Zygmunt (2000): Modernidad líquida, trad. Mirta Rosenberg en colaboración con Jaime Arrambide Squirru, Buenos Aires: Fondo de Cultura Económica de Argentina.

ВНАВнА, Homi K. (2004) [1994]: The Location of Culture, New York: Routledge.

Bielsa, Esperança (2016): Cosmopolitanism and Translation. Investigations into the experiences of the foreign, London/New York: Routledge.

BIElSA, Esperança y Susan Bassnett (2009): Translation in Global News, London/New York: Routledge.

BeARd, Mary (2017): Women and Power. A Manifesto, New York: Liveright.

BERGER, John (1972): Ways of Seeing, London/New York: Penguin Books.

Cronin, Michael (2003): Translation and Globalization, London/New York: Routledge.

Federici, Eleonora y Marilena Parlati (2018) (eds.): The Body Metaphor: Cultural Images, Literary Perceptions, Linguistic Representations, Perugia: Morlacchi.

Foucault, Michel (2002) [1975]: Vigilar y castigar. El nacimiento de la prisión, Buenos Aires: Siglo veintiuno editores Argentina.

Fowler, Jie, Reisenwitz, Timothy y Carlson, Les (2015): «Deception in cosmetics advertising: Examining cosmetics advertising claims in fashion magazine 
ads», Journal Of Global Fashion Marketing, 6/3, 194206, doi: 10.1080/20932685.2015.1032319

FRASER, Mariam y Monica Greco (2007) [2005]: «Introduction», en Mariam Fraser y Monica Greco (eds.), The Body. A Reader, London/New York: Routledge Student Readers, 1-42.

Gallego, Juana (2013): De reinas a ciudadanas: medios de comunicación, ¿motor o rémora para la igualdad?, Barcelona: Aresta.

GentZler, Edwin (2017): Translation and Rewriting in the Age of Post-Translation Studies, New York/London: Routledge.

GiL Calvo, Enrique (2000): Medias miradas. Un análisis cultural de la imagen femenina, Barcelona: Anagrama.

GodAYol, Pilar (2018): «Translation and Gender»», en Roberto Valdeón y $\mathrm{M}^{\mathrm{a}}$ del Carmen África Vidal Claramonte (eds.), Routledge Handbook of Spanish Translation Studies, London/New York: Routledge, 102-117.

Grijelmo, Álex (2014) [2000]: La seducción de las palabras. Un recorrido por las manipulaciones del pensamiento, Madrid: Punto de lectura.

HARDING, Sue-Ann y Ovidi Carbonnell Cortés (eds.) (2018): Routledge Handbook of Translation and Culture, London/New York: Routledge.

Hernández Guerrero, Ma José (2018): «Journalistic Translation», en Roberto Valdeón y $\mathrm{M}^{\mathrm{a}}$ del Carmen África Vidal Claramonte (eds.), Routledge Handbook of Spanish Translation Studies, London/New York: Routledge, 2092-2108.

Hernández Guerrero, Ma José (2012): «La traducción al servicio de una línea editorial: la primavera árabe en el diario El País», en Roberto A. Valdeón (ed.) Journalisme et Traduction/Journalism and Translation, Méta, 57/4, 960-976.

HK Golfer (2017): «Rolex \& Women's Golf: Uphold High Standards of Excellence», diciembre de 2017, <https:// issuu.com/hkgolfer/docs/1712rolexwomen>

Hofstede, Geert (1998) (ed.): Masculinity and femininity: The taboo dimension of national cultures, London: Sage.

JAKOBson, Roman (1959): «On Linguistic Aspects of Translation», On Translation, 3, 30-39.

Montes Fernández, Antonia (2007): Traducción y globa- lización. Análisis y perspectivas del fenómeno publicitario (inglés-español-alemán), Granada: Comares.

NARDI, Valeria (2011): «The Translation of Gender Stereotypes in Advertising», en Eleonora Federici (ed.) Translating Gender, Bern: Peterlang, 117-127.

PÁez Rodríguez, Alba (2016): «Análisis de la (no) traducción en las revistas de moda y belleza españolas desde la teoría del contrapunto: lenguas y capitales en la construcción de un discurso de autoridad», en $\mathrm{M}^{\mathrm{a}}$ Rosario Martín Ruano y África Vidal Claramonte (eds.), Traducción, medios de comunicación, opinión pública, Granada: Comares, 99-118.

Pedersen, Daniel (2014): «Exploring the concept of transcreation - transcreation as 'more than translation'?», The Journal of Intercultural Mediation And Communication, 7, 57-71. <https://iris.unipa.it/ retrieve/handle/10447/130535/197987/cultus\%20 _7_2014.pdf\#page $=57>$.

PlazA, Sara (2018): «Es vital que las chicas tengan referentes de científicas para sentirse identificadas», Público, 10 de octubre de 2018, <https://www.publico.es/sociedad/dia-internacional-mujer-ninaciencia-vital-chicas-tengan-referentes-cientificas-sentirse-identificadas.html>.

PotTer, Jonathan (1996): La representación de la realidad. Discurso, retórica y construcción social, trad. Genís Sánchez Barberán, Barcelona: Paidós.

Rangel Amo, Guadalupe y María del Mar Ramírez Alvarado (2018): «Las mujeres en la prensa deportiva española durante los juegos olímpicos de Río 2016», Estudios sobre el mensaje periodístico, 24/2, 1595-1613.

Rodríguez Arcos, Irene (2019): Traducción y violencia simbólica. Post-traducciones del cuerpo femenino en los medios de comunicación, Granada: Comares.

SALONGA, Bianca (2017): «Rolex Celebrates the Pioneering Spirit of Women», Forbes, 21 de marzo de 2017, <https://www.forbes.com/sites/biancasalonga/2017/03/21/the-pioneering-spirit-of-womencelebrated-by-rolex/>.

SAntaemilia, José (2014) [2005] (ed.): Gender, Sex and Translation: The Manipulation of Identities, London: Routledge.

Subiela Hernández, Blas José (2010): El diseño de revistas 
32 como lenguaje: fundamentos teóricos, Tesis doctoral. Universidad Católica San Antonio.

Toury, Gideon (1980): «Equivalence and Non-Equivalence as a Function of Norms», en Gideon Toury (ed.), Search of a Theory of Translation, Tel Aviv: Porter Institute, 63-70.

Turner, Bryan S. (2009): «The Sociology of the Body», en Bryan S. Turner (ed.), The New Blackwell Companion to Social Theory, Malden: USA, 513-532.

Түмосұко, Maria у Edwin Gentzler (2002) (eds.): Translation and Power, Amherst/Boston: University of Massachusetts Press.

VALDEón, Roberto (2020): «Gatekeeping, ideological affinity and journalistic translation», Journalism. <https://doi.org/10.1177/1464884920917296>

VALDEÓn, Roberto (2018): «Translation and Culture in Mainstream Media and Journalism», en Sue-Ann Harding y Ovidi Carbonnell Cortés (eds.), Routledge Handbook of Translation and Culture, London/ New York: Routledge, 558-573.

VALDeón, Roberto y Ma del Carmen África Vidal Claramonte (eds.) (2018): Routledge Handbook of Spanish Translation Studies, London/New York: Routledge.

VALDÉs, Cristina (2004): La traducción publicitaria: comunicación y cultura. Castelló de la Plana: Servei de publicacions de la Universitat Jaume I.

Vidal Claramonte, Ma del Carmen África (2018a): «The Body as a Semiotic System of Representation», en Eleonora Federici y Marilena Parlati (eds.), The Body Metaphor: Cultural Images, Literary Perceptions, Linguistic Representations, Perugia: Morlacchi Editore, 17-26.

Vidal Claramonte, Ma del Carmen África (2018b): La traducción y la(s) historia(s): nuevas perspectivas en la investigación, Granada: Comares.

Vidal Claramonte, Ma del Carmen África (2013): «Estereofonías de la traducción», en Icíar Alonso, Jesús Baigorri y Helen Campbell (eds.), Traducir el Derecho. Cuestiones teóricas y metodológicas, Granada: Comares, 15-22.

Vidal Claramonte, $M^{\mathrm{a}}$ del Carmen África (2012): «El lenguaje de las revistas femeninas españolas: la (no) traducción como ideología», Meta: Journal Des Traducteurs, 57/4, 1029-1045. doi: 10.7202/1021231ar 